\title{
Refractory Malignant Bone Neoplasm
}

National Cancer Institute

\section{Source}

National Cancer Institute. Refractory Malignant Bone Neoplasm. NCI Thesaurus. Code C150525.

Malignant bone neoplasm that is resistant to treatment. 